East African Medical Journal Vol. 79 No. 3 March 2002

MULTIDIMENSIONAL HEALTH LOCUS OF CONTROL SCALES: APPLICABILITY AMONG GHANAIAN ADOLESCENTS

A. N. Astrøm, DDPH, PhD, Associate Professor, Department of Odontology, Community Dentistry, Centre for International Health,

University of Bergen, Norway and D. Blay, MPhil (Dentist), Centre for International Health, University of Bergen, Bergen, Norway.

Request for reprints to: Dr. A. N. Astrøm, Centre for International Health, Armauer Hansen Building, N-5021, Bergen, Norway.

\title{
MULTIDIMENSIONAL HEALTH LOCUS OF CONTROL SCALES: APPLICABILITY AMONG GHANAIAN ADOLESCENTS
}

\author{
A. N. ASTRØM and D. BLAY
}

\begin{abstract}
Background: Primary preventive approaches are likely to be more effective if the motivational factors of health behaviours are known. Beliefs about control over health outcomes are among the most important motivational factors, commonly assessed with the multidimensional health locus of control scale (MHLC).

Objectives: To examine the validity, reliability and cross-cultural correspondence of the MHLC scales among Ghanaian adolescents.

Design: Cross-sectional questionnaire survey.

Setting: Secondary schools in the Awutu-Effutu-Senya district of Ghana, 1998.

Subjects: The analysis is based on 504 secondary school children constituting a response rate of $86 \%$.

Intervention: Non-intervention study.

Main outcome measures: The MHLC score comprising beliefs in own control over health, beliefs in provider control over health and beliefs in chance health outcomes.

Results: Fifty per cent urban and $\mathbf{4 8 \%}$ rural pupils recorded health as an important issue. More than $90 \%$ of the participants were correctly informed regarding oral health consequences of tooth cleaning, tobacco smoking and sugar consumption. Exploratory factor analysis gave two sub-factors of the MHLC corresponding to internal and provider control over health and having internal consistency reliability of 0.72 and 0.76 , respectively.

Conclusion: The results lend support to the cultural correspondence of the MHLC instrument, several aspects of its validity and internal consistency reliability.
\end{abstract}

\section{INTRODUCTION}

Ghana, like other developing countries is experiencing an increase in non-communicable diseases(1). Oral diseases, which previously have not been a problem are now of growing concern $(2,3)$. To counteract emerging life style related diseases the Ghanaian health authorities need to adopt primary preventive approaches. From a practical point of view such efforts may be more effective if the motivational factors that contribute to the initiation and maintenance of health-related behaviour are known and can thus be manipulated.

Health locus of control: One of the most intriguing potential determinants of health behaviour is the health locus of control construct (HLC), a key concept in Rotter's social learning theory (SLT), widely used to characterise a person's beliefs about control over health outcomes(4). Over the years, multi-dimensional health locus of control (MHLC) scales have been developed. These scales typically measure three dimensions of beliefs, belief in one's own control overhealth (internal health locus of control, IHLC); belief in provider control over health (powerful others health locus of control, PHLC) and belief in chance health outcomes (chance health locus of control, CHLC)(5). Two different forms of this instrument are available each containing three entirely positively worded six-item scales. Originally validated, the internal consistency reliability was recorded to be satisfactory with alpha values ranging from .67 to $.77(5)$.

Subsequent psychometric research on the MHLC instrument has, however, produced equivocal findings. A number of studies have revealed reliability closely approximating original coefficients and have the threefactor solution as satisfactory (6-8). Support for the threedimensional structure of the MHLC instrument has even been obtained from an adapted version employed with elementary school children and adolescents $(9,10)$, although sub-scale reliability and independence were less than expected for both 13- and 15-year olds. Nevertheless, contradictory evidence has gradually accumulated. Although studies of Brazilian and Italian adults evidence cross-cultural correspondence for the three-dimensional MHLC structure beyond North America(6,1 1), West failed to replicate sub-scale independence for lower-class Black American and Mexican American men(12). In an investigation of the psychometric properties of MHLC among white college students, O'Looney and Barrett(13) found the proposed three-factor structure for women but 
only a two-factor structure for men. Studies of cigarette smokers (14), medical and dental students(15) and hospital staff $(16)$ have failed toconfirm a clear distinction between the PHCL and CHLC scales. Rather this evidence suggests a two-factor construct composed predominantly of items assessing one internal and one external dimension.

The MHLC scale has been used in a number of studies investigating various health conditions and behaviours with a wide range of populations (17). At its simplest, the SLT(4) suggests that high internals take an active responsibility for their own health and thus are likely to engage in health-promoting behaviours. Those who score highly on the chance dimension tend to engage less in health-protective and more in health-damaging behaviours. The implications of scores on the PHLC are less clear. Research on these issues has produced mixed results. Some studies have found significant positive associations between IHLC beliefs and indices of preventive health behaviour, while others have failed to find such relationships(17). Moreover, negative relationships between preventive health behaviours and both CHLC and PHLC have been reported $(18,19)$.

Since most studies of the MHLC instrument have been performed with adult populations in occidental settings, its robustness across cultural boundaries has yet to be established. So far, no study has been published on the psychometric properties of the MHLC instrument among African adolescents. This paper therefore aims to examine whether a three-dimensional orientation would be supported in a sample of Ghanaian secondary school pupils. The specific purpose was to explore the factorial structure of the MHLC instrument estimate the internal consistency reliability of the obtained sub-scales and to report on their correlation with theoretically derived variables.

\section{MATERIALS AND METHODS}

Data were collected during May and June 1998, in the Awutu-Effutu-Senya district of Ghana, located 56 kilometres from the capital city of Accra. The study population consisted of pupils, enrolled in the five secondary schools of the district. A total of three secondary schools were selected using a one-stage stratified random sampling procedure. It was decided to target all second-year students in the selected schools. Permission to conduct the study was obtained from the District Health Management Team, the Ghana Education Service in Winneba and the school authorities. Verbal consent to participate was obtained from each student. To ensure confidentiality and minimise response bias, neither school authorities nor the teachers were present in the class- room during the data collection.

The eligible sample consisted of 583 second-year pupils. A total of 504 adolescents $(47.4 \%$ females and $52.6 \%$ males) responded, yielding a response rate of $86 \%$. For the total sample, the mean age was 16.6 , (s.d.=1.1, range 14-18). Although the mean age of boys was slightly higher than that of girls, there was no statistically significant age difference between the sexes. The participants completed questionnaires at school within one hour. Trained researchers supervised the data collection and the students were free to ask questions for clarification at any time. The questionnaires were designed to match the literacy level of the target population and few or no major obstacles were encountered during the data collection. Neither did the pre-test lead to any major changes of the questionnaire items.

Measurements: Multidimensional health locus of control instrument (MHLC) developed by Wallston et al (5) comprises 18 items, representing three different sub-scales, denoted IHLC, PHLC, CHLC, respectively. Each of the three sub-scales includes six items. The questionnaire used in this study retained the original version of the IHLC and CHLC scale, whereas four items related to the PHLC were included. The wording of each item and descriptive statistics is shown in Table 3. Each item required the respondents to express their degree of agreement and disagreement using a 5-point Likert scale ranging from $1=$ "Strongly disagree" to $5=$ "Strongly agree".

Socio-demographic variables pertinent to this paper comprised gender ("female" $=1$, "male" $=2$ ) and region where raised ("rural"=1, "urban"=2).

Oral hygiene behaviour was based on a sum score derived from the following questions: "How often do you use tooth picks?" and " How often do you clean your teeth?" Response categories ranged from $\mathrm{l}=$ "never" to $4=$ "several times a day" The lower the score on this sum index the less frequent engagement in oral hygiene behaviour ( mean $=5.2, \mathrm{SD}=1.1$; range $=3-8$ ).

Intention to avoid sugared snacks and drinks was measured by a sum score of two items, for example: "How likely or unlikely do you think it is that you will avoid daily intake of sugared snacks and drinks in the future?" Responses were given on a scale ranging from $1=$ "very unlikely" to $5=$ "very likely". The higher the score on this additive index, the stronger the intention to avoid sugared snacks and drinks in the future (mean=6.9 $\mathrm{SD}=1.7$; range $=2-10$, Cronbach's alpha=86)

Oral health knowledge, the generally assumed result of information seeking behaviour was assessed by a sum score derived from eight statements regarding oral health, for example, "Irregular tooth brushing might cause tooth decay". Response categories were given as $1=$ "no" and $2=$ "yes". The lower the score on the sum index the lower the reported level of oral health knowledge (mean $=14.4, \mathrm{SD}=1.0$, range $=11-16$ ).

Health value comprised the four item- scale suggested by Lau et al(20). "If I do not have good health, I do not have anything"; "There are many things I care about more than my health and oral health"; "Good health is only of minor importance in a happy life"; "There are few things more important than good health". Response categories ranged from $1=$ "strongly disagree" to $5=$ "strongly agree". The last statement of the sum score was constructed from the remaining three items. The lower the score on the health value scale the less value placed on health by the respondents (mean $=13.3, \mathrm{SD}=1.3$, range $=5-15$. Cronbach's alpha= .72).

Analysis: The data were analysed using the Statistical Package for Social Science, SPSS version 8.0. Frequency distribution analyses were used on all variables separately for boys and girls raised in urban and rural areas, respectively. Principal component analysis (PCA) yielded information about how many factors or dimensions are needed to provide a sufficient description of the MHLC items examined(21). The optimal number of factors was established on the basis of three criteria: Kaiser's Eigenvalue rule, extra percentages explained by the added factors, and the screen test. Internal consistency reliability was calculated using coefficient alpha(22). Inter-correlations between scales were obtained by use of Pearson's product moment correlation. Pearson's product moment correlation coefficients were also computed to assess the bivariate relationship between the sub scales derived from PCA and a set of external variables. Although many of the external variables were based 
upon ordinal scales they were treated as if they were at least interval scaled - a procedure that does not seem to invalidate the conclusion under most circumstances(23).

\section{RESULTS}

The percentage distributions of Ghanaian adolescents according to socio-demographic characteristics, oral health related behaviour, oral health related knowledge and health value are shown in Tables 1 and 2 .

Table 1

Absolute $(n)$ and relative $(\%)$ distribution of subjects according to gender and region where raised

\begin{tabular}{lrrrrr}
\hline Socio-demographic factors & \multicolumn{2}{c}{ Urban } & \multicolumn{2}{c}{ Rural } \\
& No. & $\%$ & \multicolumn{1}{c}{ No. } & $\%$ \\
\hline Females & 146 & 51.6 & 93 & 42.1 \\
Males & 137 & 48.4 & 128 & 57.9 \\
\hline
\end{tabular}

Table 3 shows the factor analytic results of the 16 MHLC items in the sample of Ghanaian adolescents. PCA initially extracted three factors with Eigen value $>1.00$. However, the last extracted factor had an Eigenvalue only marginally above $1.00(1.1)$ and explained a rather small portion of the total item variance $(6.9 \%)$. Furthermore, the results of the varimax rotated solution showed that items were poorly grouped according to the three sub scales in that many items loaded meaningfully $(>0.25)$ on more than one factor. Consequently, the programme was instructed to extract two factors that explained $41 \%$ of the total item variance in the un-rotated solution. As shown in Table 1, the IHLC items loaded mainly on Factor 2, whereas the PHLC - and CHLC items loaded together on Factor 1. The loadings were by and large substantial $(>0.40)$ and pure, that is, most items loaded meaningfully $(>0.25)$ on only one factor. Nevertheless, some items had a factor complexity greater than 1 and loaded significantly on two factors (that is numbers 2,3 and 7). Factor I was

Table 2

Percentage distribution of respondents who engaged in oral hygiene behaviour once a day, intended to avoid sugared snacks and drinks, answered correctly to knowledge statements and valued their health strongly according to gender and residence where raised

\begin{tabular}{|c|c|c|c|c|c|c|}
\hline & \multicolumn{4}{|c|}{ Urban } & \multicolumn{2}{|c|}{ Rural } \\
\hline & $\begin{array}{r}\% \text { All } \\
(n=283)\end{array}$ & $\begin{array}{r}\% \text { Female } \\
(\mathrm{n}=146)\end{array}$ & $\begin{array}{c}\% \text { Male } \\
(n=137)\end{array}$ & $\begin{array}{r}\% \text { All } \\
(\mathrm{n}=221)\end{array}$ & $\begin{array}{r}\% \text { Female } \\
(\mathbf{n}=93)\end{array}$ & $\begin{array}{l}\% \text { Male } \\
(\mathrm{n}=128)\end{array}$ \\
\hline \multicolumn{7}{|l|}{ Oral health behaviour } \\
\hline Use of toothpicks & 12 & 16 & 6 & 4 & 4 & 3 \\
\hline Tooth cleaning & 49 & 48 & 50 & 48 & 40 & 56 \\
\hline Intention to avoid snacks & 43 & 55 & 51 & 53 & 47 & 40 \\
\hline \multicolumn{7}{|l|}{ Oral health knowledge } \\
\hline Tooth cleaning-gum disease & 96 & 95 & 96 & 97 & 97 & 97 \\
\hline Sugar-tooth decay & 93 & 93 & 92 & 96 & 95 & 96 \\
\hline Fluoride-pitted teeth & 63 & 65 & 59 & 72 & 68 & 74 \\
\hline Tobacco -oral cancer & 96 & 95 & 96 & 95 & 95 & 95 \\
\hline \multicolumn{7}{|l|}{ Oral health value } \\
\hline Health is very important & 53 & 48 & 53 & 48 & 51 & 54 \\
\hline
\end{tabular}

Table 3

Varimax rotated factor structure of the $16 \mathrm{MHLC}$ items, explained variance and descriptive statistics (means, $M$, standard deviations, SD) for each single item. All loading above 0.25 are shown.

\begin{tabular}{|c|c|c|c|}
\hline \multirow[t]{2}{*}{ Item wording and number } & \multicolumn{2}{|c|}{ Factor } & \multirow[t]{2}{*}{$\mathrm{M}(\mathrm{SD})$} \\
\hline & 1 & 2 & \\
\hline 2. Sickness is due to my own behaviour & .45 & -.32 & $2.0(0.9)$ \\
\hline 3. Regular contact with doctor avoids sickness & .35 & -.29 & $3.8(1.1)$ \\
\hline 4. Chance affects my health and oral health & .50 & & $1.8(0.9)$ \\
\hline 6. My family is important for my health & .26 & & $4.1(1.0)$ \\
\hline 8. My recovering from illness is due to luck & .71 & & $1.9(1.1)$ \\
\hline 9. Health professionals control my health & .68 & & $2.3(1.1)$ \\
\hline 10 My health is a matter of good fortune & .77 & & $1.9(1.0)$ \\
\hline 13 No matter what I do I will get ill & .62 & & $2.0(0.8)$ \\
\hline 14 If it is meant to be so I will stay healthy & .73 & & $2.3(1.0)$ \\
\hline 16 My health depends on advice of the doctor & .75 & & $2.0(0.9)$ \\
\hline 1 If sick, recovering depends upon my behaviour & & .51 & $4.0(0.9)$ \\
\hline 5 I am controlling my health and oral health & & .59 & $3.9(0.8)$ \\
\hline 7 When sick I am to be blamed & -.37 & .56 & $3.5(0.9)$ \\
\hline 11. My own behaviour mainly affects my health & & .70 & $4.0(0.9)$ \\
\hline 12 If I take care I can avoid illness & & .66 & $4.5(1.0)$ \\
\hline 15. If I take the right actions I can stay healthy & & .65 & $4.3(0.8)$ \\
\hline
\end{tabular}


defined by items no $2,3,4,6,8,9,10,13,14,16$ because they all loaded highly on this factor, whereas factor 2 consisted of item no $1,5,7,11,12,15$. The $16 \mathrm{MHCL}$ items included in the two factors specified above were combined into two sum scores: the combined PHLC/CHLC scale, denoted external health locus of control or EHLC $(\alpha=.76, \mathrm{M}=24.4$. $\mathrm{SD}=5.2$, range $=1040)$, and the IHLC scale denoted internal health locus of control $(\alpha=72, M=24.6, S D=5.2$, range $=13$ 30 ), respectively. The association between these two scales assessed on the IHCL and EHCL scales indicate low levels of internal and external control, respectively.

\section{Table 4}

Pearson's correlation between the IHLC and EHLC sub-scales and external variables; gender, region where raised, father's education, mother's education, oral health knowledge, oral hygiene behaviour. the intention to avoid intake of sugared snacks and health value. Ghanaian adolescents $(n=504)$

\begin{tabular}{lcc}
\hline External variable & IHCL & EHCL \\
\hline Gender & .033 & -.031 \\
Region where raised & $-.09^{*}$ & $.18^{* *}$ \\
Oral health knowledge & $.10^{*}$ & $-.24^{* *}$ \\
Oral hygiene behaviour & -.04 & $.16^{* *}$ \\
Intention to avoid sugar & $.28^{* *}$ & $-.26^{* *}$ \\
Health value & $.28^{* *}$ & -.07 \\
\hline
\end{tabular}

${ }^{*} \mathrm{p}<0.001 ;{ }^{*} \mathrm{p}<0.05 ;$ n.s. $=$ not statistically significant

Table 4, presents the relationships between the two sub-scales derived from the PCA and a set of selected external variables for the whole sample. Generally, the statistically significant correlations are weak to moderate, but do differ consistently across the IHLC and the EHLC scales. As depicted in Table 2, region were raised correlated positively $(r=.18, p<0.001)$ and negatively $(r=-.09, p<0.05)$ with the EHLC and IHLC scales, respectively. Whereas the IHLC scale was positively associated with the indices of oral health knowledge $(r=.10, p<0.05)$ and the intention to behave preventively (avoid sugar) $(r=.28, p<0.001)$, the EHLC scale correlated negatively with those same external criteria. Furthermore, the EHLC scale correlated exclusively $(\mathrm{r}=16, \mathrm{p}<0.001)$ with oral hygiene behaviour, whereas the IHCL scale correlated exclusively $(r=28$, $\mathrm{p}<0.001$ ) with health value.

\section{DISCUSSION}

The data from the administration of the MHLC instrument to secondary school pupils justifies the choice of a simple dichotomous concept over the original threedimensional one. This conclusion is based upon the results of a PCA and the fact that the two dimensions behaved differently when confronted with external criteria. The factor structure of the instrument and its associations with theoretically derived variables provide further support for the validity of the health locus of control construct. Moreover, the present results obtained among Ghanaian adolescents lend support to control perspective $(6,11)$.
The inter-scale correlation coefficients of the IHLC, PHLC and CHLC indicated relationships that differed considerably from the pattern initially described by Wallston et al(5). Most noteworthy were the reasonably' strong $(\mathrm{r}=.51)$ positive correlation between CHLC and PHLC, suggesting a lack of distinctiveness between those sub-scales. On the basis of the normative data of adult populations(5), this interscale correlation would have been expected to be statistically independent. However, this finding accord with those obtained among US elementary-school children, where reasonable high positive associations between PHLC and CHLC sub scales have been reported $(9,10)$. On the other hand, as compared to IHLC mean- and alpha scale values obtained in the occidental studies, the present figures, provided among slightly older Ghanaians, tended to be higher. Such a finding coincides with the theoretical expectations that children become more internal as they age - a tendency confirmed in previous research(24). Alternatively, since increased number of response alternatives yields more reliable data(25), use of four point- rather than the original six point scales in the occidental studies might have contributed to the observed differences.

As expected, the empirical data did not match the original three- factor structure suggested by Wallston et al(5). The lack of distinctiveness between the PHLC and CHLC scales, as evidenced by sub-scale inter correlation, and the factor analytic results cast doubt on the three dimensionality of the MHLC instrument among Ghanaian adolescents. As shown in Table 1, PCA revealed a bidimensional construct with the PHLC and CHLC items loading together on a single factor. In conjunction with similar findings obtained previously(13-16), it seems reasonable to suggest that use of the IHLC scale and the combined PHLC and CHLC scales might strengthen the validity of the MHLC instrument. This finding is at odds with the main conclusion derived from empirical studies of North American elementary school children(9), but is consistent with that of Stanton et al (10) who found a twofactor solution to be most parsimonious among 13-year olds. The inconsistency in the results obtained with the MHLC instrument may be a function of the methods of analysis, for instance the use of traditional exploratory, rather than more powerful confirmatory factor analytical approaches. In light of these comparisons, it should not be forgotten that instruments are sample specific in the way they operate. The notion that baseline factor models should not even be expected to be identical across different population groups(26) points to the importance of reexamining the psychometric properties of widely used measures.

Although the results from the PCA indicated that the health locus of control disposition should be considered as two distinguishable dimensions, the IHLC and EHLC scales correlated moderately and inversely. Thus, higher levels of internal control appear to imply lower levels of external control and vice versa on the part of the Ghanaian respondents. In view of the fact that several items (nos. 2 , 
3 and 7) loaded meaningfully on more than one factor, the observed inter-correlation between IHLC and EHLC subscales is not that surprising. The fact that these same items also received low communalities in the PCA, makes them prime candidates for exclusion or substitution in order to improve the psychometric properties of the MHLC instrument among Ghanaian adolescents.

The evidence that the IHLC and EHLC scale correlated differently with some external criteria tends to confirm their distinctiveness (27). As shown in Table 2, the direction of the associations was fairly consistent with what is expected from theory, the higher the level on the internal dimension and the lower the level on the external one, the more active responsibility for health in terms of intending to avoid sugared snacks. Moreover, the pattern of associations between the two sub-scales and oral health related knowledge corroborates previous studies describing internals as more informed than externals regarding different health conditions (28). Contrary to the EHLC, the IHLC scale was rather unsuccessful in discriminating between those Ghanaians who engaged in oral hygiene performance and those who did not. Although, Stepthoe $e t$ al(29) found positive associations between the PHLC dimension and performance of health enhancing actions, there is little evidence to support the view that externals are more likely to act preventively. Notably, a couple of studies have suggested the opposite(17). Most probably, these results may be specific to the cultural context in which they occurred and come largely from the way in which the items of the MHLC scales were interpreted. Externality might be viewed rather differently in the Ghanaian as compared to the Western culture. Thus, a situation considered to be under external control may not necessarily be viewed as encouraging in-action. It is even possible to argue that Ghanaian adolescents' faith in the health authorities adds credence to health education advice, encouraging them to engage frequently in oral hygiene performance. Health externality may be conducive to oral hygiene performance especially if the initial impetus for performance comes from health professionals' advice or from attendance of a formal health education programme.

To summarise, the present study suggests that the MHLC instrument comprise two dimensions of health locus of control beliefs reflecting internal and external influence over health. Additionally, the present data provide some support for the construct validity of the MHLC concept by confirming the theoretically expected associations with preventive health behaviours. The results obtained among Ghanaian adolescents corroborate previous research demonstrating cross-cultural adequacy of the health locus of control construct. However, a more extensive construct validation of the MHLC instrument should precede its application among Ghanaian adolescents. Additional research on this issue should consider reconstructing the MHLC items showing lower reliability and should preferably employ confirmatory factor analysis.

\section{ACKNOWLEDGEMENTS}

The Centre for International Health have provided permission to publish the present data. We gratefully acknowledge the advice of Professor Ola Haugejorden, Department of Odontology-Community Dentistry, and Professor Jostein Rise, Department of Social Psychology, University of Bergen, Norway for valuable assistance concerning different aspects of this project. We are indebted to the Health Management Team, Winneba, Ghana Education Service, Winneba, for their support and permission to conduct this study. We also acknowledge with thanks the financial support given by the Norwegian State Educational Loan Fund and the Faculty of Odontology, University of Bergen.

\section{REFERENCES}

1. Nissinen, A. and Kiangi, G. The increasing importance of chronic diseases. In: Lankinen KS, Bergstrøm S, Makela P.H. and Peltomaa M, (eds.) Health and Disease in Developing Countries. London: Macmillan. 1994.

2. Ministry of Health, Ghana. The road to a healthier future for Ghana Accra: Ministry of Health. 1997.

3. Addo-Yobo, C., Williams, S.A. and Curzon, M.E.J. Dental caries experience in Ghana among 12-year old urban and rural school children. Caries Res. 1991; 25:311-314.

4. Rotter, J.B. Social learning and clinical psychology. Englewood Cliffs, NJ: Prentice Hall. 1954.

5. Wallston, K.A., Wallston, B.S. and DeVellis, R. Development of the multidimensional health locus of control (MHLC) scales. Hlth Educ. Monogr. 1981; 6: 160-170.

6. Paine, P., Passquali, L., Sao Paulo, E., Bianchi, A.L. and Solha, A.C. Psychometric Properties of the Brazilian health locus of control scale. Psychol. Rep. 1994; 75: 91-94.

7. Robinson-Whelen, S. and Storandt, M. Factorial structure of two health belief measures among older adults. Psychology and Ageing. 1992; 7:209-213.

8. Talbot, F., Nouwen, A and Gauthier, I. Is health locus of control a 3-factor or a 2-factor construct? J. Clin. Psychol. 1996; 52: 559-568.

9. Thompson, B., Webber, L. and Berenson, G. Factor structure of a children's health locus of control measure: A confirmatory maximum likelihood analysis. Educ. Psychol. Measurement. 1987; 47:1071-1080.

10. Stanton, W.R., Shyamala, N.R. and Langley, J. Stability in the structure of health locus of control among adolescents. Brit. J. Clin. Psych. 1995; 34: 279-284

11. Gala, C., Musicco, F., Durbano, F. and Cesana, B. Italianvalidation of the multidimensional scale of "Health Locus of Control". New Trends in Experimental and Clinical Psychiatry. 1995; 11: 79-86.

12. West, R.B. The effects of ethnic background and health locus of control on health maintenance practices related to risk factors of heart disease. Unpublished Master's thesis, Michigan: State University. 1980.

13. O'Looney, B.A. and Barrett, P.T. A psychometric investigation of the Multidimensional Health Locus of Control Questionnaire. Brit. J. Clin. Psych. 1983; 22: 217-218.

14. Cohelo, R.J. A psychometric investigation of the Multidimensional Health Locus of Control Scales with cigarette smokers. J. Clin. Psychol. 1985; 41:372-376.

15. Winefield, H. Reliability and validity of the Health Locus of Control Scale. J. Pers. Assess. 1982; 46: 614- 619.

16. Cooper, D. and Fabroni, M. Toward a more valid and reliable health Locus of Control Scale. J. Clin. Psychol. 1988; 464: 536-540.

17. Norman. P. and Bennett, P. Health locus of control. In M. Conner P. Norman (Eds.). Predicting Health Behaviour (pp 62-94). Buckingham: Open University Press. 1996.

18. Nemeck, M.A. Health beliefs and breast self-examinations among black women. Hlth Values. 1990; 14: 41-52.

19. Ludenia, K and Donham, G.W. Dental outpatients: Health locus of control correlates. J Clin Psychol. 1983; 39: 854-858.

20. Lau, R.R., Hartman, K.A. and Ware, J.E. Health as a value: Methodological and theoretical considerations. Hlth Psychol. 1986; 5: $25-43$. 
21. Kim, J.O. and Mueller, C.W. Factor analysis: Statistical methods and practical issues. (Sage University Paper Series on Quantitative Applications in the Social Sciences, 07014). Beverly Hills: Sage Publications, 1978.

22. Cronbach, L.J. Coefficient alpha and the internal structure of tests. Psychometrika. 1951; 16: 297-334,.

23. O'Brien, R.M. The use of Pearson's $r$ with ordinal data. Amer. Sociol. Rev. 1979; 44:851-857.

24. Wolf, T.M., Sklov, M.C., Hunter, S.M. and Berenson, G.S. Factor analytic study of the Children's Nowicki- Stricklaland Locus of Control Scale. Educ. Psychol. Measurement. 1982; 42: 333-337.

25. DeVellis, R.F. Scale development. Theory and application. Applied Social Research Methods series. Sage Publications, London; 1991.
26. Byme, B.B. A primer of Lisrel: Basic applications and programming for confirmatory factor analytic models. New York: Springer. 1989.

27. Carmines E.G. and Zeller R.A. Reliability and validity assessment Series: Quantitative applications in the social sciences. Beverly Hills: Sage Publications. 1979.

28. Wallston, K.A. and Wallston, B.S. Health locus of control scales. In H. Lefcourt (ed.). Advances and innovations in locus of control research (pp 65-95). New York: Academic Press, 1981.

29. Stepthoe, A., Wardle, J., Vinck, J., Tuomisto, M. and Holte, A., et $a l$. Personality and attitudinal correlates of healthy and unhealthy lifestyles in young adults. Psychol. Hlth. 1994; 9:331-343.

Dear Sir

\section{SCIENTIFIC LETTER}

\section{RE: FREQUENTLY RECURRING MYXOID LIPOSARCOMA}

Myxoid liposarcoma represents a continuous morphological spectrum including pure myxoid liposarcoma, mixed (myxoid/ round cell) liposarcoma and pure round cell liposarcoma(1). The tendency of this tumour to metastasise to other soft tissues has been documented and the abdominal wall being the second most common site after the retroperitoneum(2). The differentiation is essential as the metastasis are of aggressive nature and needs urgent and adequate surgical excision.

We report here a sixty-year old female who has been followed in Khartoum Teaching Hospital since 1975 when she presented with a pelvic swelling. Total hytertectomy was done and the histopathology revealed fibrosarcoma. She gave a history of few previous excisions from different external sites mainly abdominal wall, thigh and trunk since 1956. Since then she used to present with a recurrence every one to two years at sites ranging from the abdominal wall, thigh, groin and perineum, all were reported as fibrosarcoma. During the previous two years she developed four recurrences with more aggressive nature of fungation and ulceration. She was given postoperative radiotherapy following the last two excisions. Histopathology of the last specimen was done by one of the authors(ElHassan) who reported a $10 \mathrm{~cm}$ lobulated mass.

Microscopically several sections showed variegated appearance. In the major part of the section the cells were polygonal or spindle-shaped with large vesicular nuclei and prominent nucleoli. Some multinucleated tumour cells were less seen. In other areas the tumour showed myxomatous changes, the cells being stellate in appearance. In many foci the cells had a vacuolated cytoplasm. There were several mitosis. In frozen section the cells were rich in lipid.

The acceptable classification of soft tissue sarcomas is based on the putative cell of origin of each tumour(3). Competent pathologists differ in attaching a histogenic label to types of soft tissue sarcoma. Peasant and colleagues reviewed 216 sarcoma cases and reported concordance in histopathological diagnosis in only $66 \%(4)$. All previous histopathology reports on this patient were not available, however available ones $(n=12)$ were reported as fibrosarcomas except the last which had been reported by one of the authors as non-pure myxomatous liposarcoma.

Silva et al (5) reported a 60-year old male with multicenteric multifocal synchronus myxoid liposarcoma exhibited over six years. Genetic studies suggested a common aetiological factor that was not yet being identified. Our patient ran an exceptional long benign course with absolutely disease free intervals during the first three decades. A similar case with a matching survival had been reported by Fukuda 1999(1). However, the tumours were getting more aggressive and occurring within shorter intervals during the last five years. No genetic studies were done in this patient.

R. Zaki, MBBS, E. N. O. Ahmed, MBBS, M. E. Ahmed, MS, FRCSI. Department of Surgery and A. M. El Hassan, MD, MRCPath, Institute of Tropical Medicine, Faculty of Medicine, P.O. Box 102, University of Khartoum, Sudan.

\section{REFERENCES}

1. Fukuda T., Oshiro Y., Yamamoto I. and Tsuneyoshi M. Long-term follow up of pure myxoid liposarcomas with special reference to local recurrence and progression to round cell lesions. Pathol. Int. 1999; 49:710 - 715 .

2. Spillane A.J., Fisher C. and Thomas J.M. Myxoid liposarcomathe frequency and natural history of non-pulmonary soft tissue metastases. Ann. Surg. Oncol. 1999; 6:389-394.

3. Enzinger, F. M. and Weiss, S.W. Soft tissue tumours. CV Mosby, St. Louis, 1988

4. Peasant C.A., Russel W.O. and Alexander R.W. et al. Soft tissue and bone sarcoma histopathology peer review. The frequency of disagreement in diagnosis and the need for second pathology opinions. The Southeastern Cancer Study group experience. J. Clin. Oncol. 1986; 4:1658 - 1661.

5. Silva D.C., de Oliveira Fiho R.S., Bevilacqua R.G., Falzoni R. and Birolini D. Multicenteric myxoid, metachronus and synchronus and multifocal liposarcoma: a report of a case. Revish do Hospital das Clinics; Faculdade de Medicina Da Universidade de Sao Paulo. 1994; 49:217 - 220 